\title{
Papers
}

\section{Valuing customers}

Received (in revised form): 3rd December, 2007

\section{Thayne Forbes}

is a joint managing director of Intangible Business, the brand valuation, strategy and development consultancy. He is a dually qualified chartered accountant and marketer and has carried out over 100 intangible asset valuations for some of the world's biggest businesses. Intangible Business is a leading intangible asset valuation consultancy, valuing intangible assets for financial, litigation and business development purposes. He has worked in all major sectors, with companies including Allied Domecq, Laura Ashley, TimeWarner, Vodafone and Woolmark, and is also a member of The Academy of Experts, The Society of Expert Witnesses and The Institute of Expert Witnesses.

Keywords customer, client, value, valuation, valuing, intangible, brand

\begin{abstract}
This paper considers the value of customers as an important intangible asset of a business. In fact, they are arguably the most important, for without customers a business would not exist. The strategic importance of customers is discussed and their interaction, as an asset, with other important business assets such as brands is analysed. The basic methodologies for valuing customers are then explained and their limitations are considered. For all the complicated valuation techniques value really boils down to business basics and common sense - management's ability to manage customer relationships profitably.

Journal of Database Marketing \& Customer Strategy Management (2007) 15, 4-10.

doi:10.1057/palgrave.dbm.3250071; published online 7 January 2008
\end{abstract}

\section{INTRODUCTION}

There is no doubt that valuing acquired intangibles such as brands, patents and customer lists makes a lot of sense rather than placing these business critical assets in the accounting black hole known as goodwill. Are the approaches applied by accountants and the resulting values, and performance measurement or simply numbers to satisfy the information requirements of investors and efficient tax planning?

Tangible assets as such machinery, Intangible Business Limited 9 Maltings Place 169 Tower Bridge Road London, SE1 3JB, UK Tel: +44 (0) 8702407386 ; Fax: +44(0) 207089 9239; e-mail: thayne.forbes@ intangiblebusiness.com; www.intangiblebusiness. com straightforward to value, their visible and to define and in most cases there is an active market from which value can be derived. In contrast, intangible assets are not so easily defined while it is rare that they however, equally valid for strategic planning

are actively traded. Consequently, any intangible valuation exercise must start with 'What?' and 'Why?' before considering 'How?'

When we talk about valuing customer relationships, the scope of definition is expansive. On the one hand, it is simply the value that customers generate for the business. On the other hand, it is purely the value of the relationship. Neither definition is more correct than the other; however, the purpose and approach for valuing each are different.

\section{'If you mean to profit, learn to please'.}

\section{Winston Churchill} corporeal nature makes them relatively easy
Customers may interact with many different parts of the business - marketing communications, at point of sale, customer service, accounts department, the product itself, etc. A positive experience throughout 
the customer cycle should foster trust and develop loyalty, therefore allowing a business to generate more revenue for less incremental expenditure. For example

- Making new customers aware of a product or service, stimulating interest and convincing them to purchase is a comparatively more expensive exercise than selling to existing customers.

- Loyal customers tend to purchase more frequently or more volume.

- Happy existing customers are more willing to purchase other products or services from a company's range and try new product or service offerings.

- Word-of-mouth recommendation lowers the overall cost of customer acquisition.

- The cost of servicing existing customers can be lower as their details are already in the system, demand predicted, delivery drivers know the location, familiarity with the product and order process means less time is taken up by sales team, etc.

- Security of future revenues, which is much higher with happy customers.

\section{Strategic view of customer relationship intangibles}

One way of considering how customer relationships create value is within the framework of Porter's value chain (Figure 1). The chain of activities gives the products more added value than the sum of added values of all activities. It may be reasonable to suggest that it is the customer's direct or indirect relationship with each of these activities that creates value for the business.

As all activities create value from and contribute to the customer relationship, it follows that the value of the business and the value of the customer relationship could be considered to be the same.

The value chain is often criticised as a dated framework that is only applicable to manufacturing industries and considers

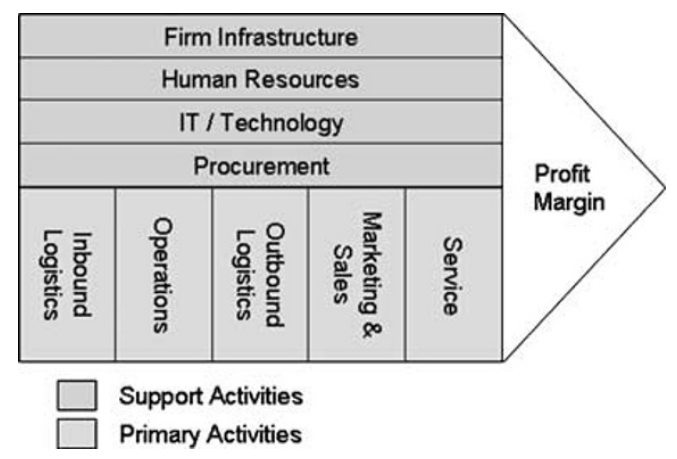

Figure 1: Porter's value chain

marketing in a silo rather than encompassing the whole enterprise.

A modern version of the value chain may resemble Figure 2.

Adopting this view of the world suggests that the value of the brand and the value of the customer relationship are the same

(Figure 2).

Although brand and customer relationships appear to be similar, there are enough subtle differences to discount using brand value as a substitute for the value of a customer relationship. For example, in business-to-business or service businesses such as consultancies or solicitors, a customer's relationship may be purely with key personnel regardless of the brand. Furthermore, a brand's sphere of influence extends beyond customer relations - a brand also has a relationship with the staff (helps recruit and retain), with suppliers (improved negotiating position) and external stakeholders (investors and government). Hence, it would be unreasonable to attribute such financial benefits generated by the brand to a customer relationship.

In contrast, there are demand drivers that cannot be attributed to the brand but can have a significant influence on the customer's relationship with a business. For example, inertia is considered to be the single biggest driver of customer retention in the banking industry; clearly, this is not attributable to brand and therefore could be considered as part of the customer 


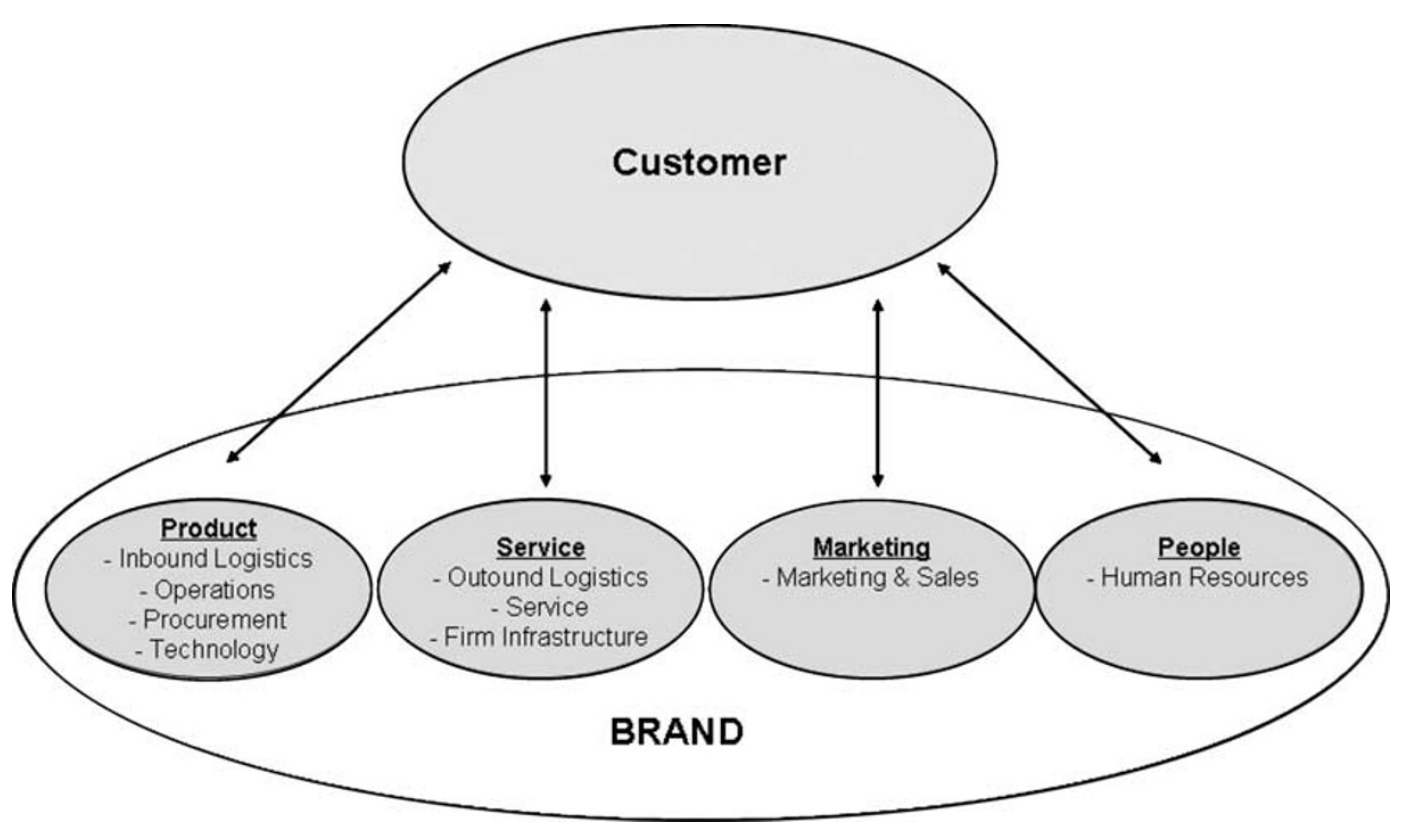

Figure 2: Modern value chain

relationship value. A convenient location is another important driver in many businesses (eg grocery stores) that is not attributable to brand and instead could be valued as part of the customer relationship or the property (Figure 3).

Overall, from the point of view of performance measurement and strategic planning, the value and definition of a firm's relationship with its customers may not be particularly relevant. It is more practical and beneficial to determine the value generated per customer from the assets employed in the business to measure performance and plan for the future.

\section{TECHNICAL VIEW OF CUSTOMER RELATIONSHIP INTANGIBLES}

The concept of customer value discussed above for strategic purposes is very different from the accepted definitions applied by those involved in carrying out technical valuations for financial reporting.

The International Accounting Standards Board (IASB) classifies intangible assets into five categories - marketing related, contract based, technology based, customer

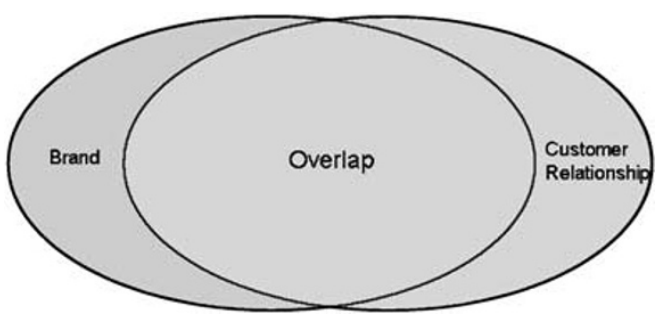

Figure 3: Overlap of brand and customer relationship

related and artistic based. For financial reporting, an intangible asset should be recognised as an asset apart from goodwill if it arises from contractual or other legal rights. An intangible asset may also be recognised only if it is separable, that is, that it is capable of being sold, transferred, licensed, rented or exchanged.

The examples of customer-related intangibles provided by the IASB are customer lists, order backlog, customer contracts and non-contractual customer relationships. A customer list can be sold or exploited while an order backlog and customer contracts have a confirmed 
income stream associated with them. Consequently, all three can be readily valued using one of the approaches discussed below. In contrast, non-contractual customer relationships are softer assets and encapsulate the unsecured future income from customers. It is rare for this latter category to be separately identified and reported on financial statements; instead, it is usually lumped into the unallocatable goodwill bucket.

\section{VALUING CUSTOMER-RELATED INTANGIBLES}

The common approaches for valuing intangible assets, including customer-related intangibles, are

Cost approach - how much did it cost to create the asset or how much it would cost to replace it?

Market approach — the amount paid for the asset or similar assets on the open market.

Income approach - the present value of future cash flows, that is, how much income the asset will generate throughout its useful life, accounting for the time value of money and associated risk.

Each method is based on strong, rational theory and yet, in practice, each method may produce starkly different values.

\section{Cost-based methodologies}

Estimating value under the historic cost approach is simply a case of summing all capital invested in creating the asset in question. In the case of a customer base, the historic cost could be considered as equivalent to the total amount of marketing investment expended.

The historic cost is distorted by the time value of money and evolvement of the competitive environment (level of saturation of product and marketing channels, competition and legislation). In a new product or service market with relatively few competitors, economic theory suggests that customer acquisition costs should be relatively low before gradually increasing as the market for new customers becomes more competitive, forcing companies to capture market share from rivals in order to realise growth. Consequently, in a mature market it is likely to cost considerably more to replace the customer base than it cost to develop originally. For this reason, the replacement cost of the asset may be deemed to be a more reasonable proxy for value. Estimating the costs required to replace an intangible asset, however, would be an extremely subjective exercise and would hinge on the estimated effectiveness of the marketing activities.

Regardless of the basis for calculating costs, it is almost always true to say that the cost of something rarely reflects its worth. Valuing customers on the basis of historic cost demonstrates the effectiveness of the marketing team rather than providing a robust indication of customer value.

Table 1 considers two start-ups after five years of operating; both companies have an identical number of customers, revenue and operating profits and yet, on a historic cost basis the value of company B's customer base is double the value of that of company A's.

This basic example demonstrates that valuing customer-related intangibles using historic or replacement cost bears no relation to the true value generated by these business critical assets. The combination of

Table 1: Historic cost valuation

\begin{tabular}{lcc}
\hline & Company A & Company B \\
\hline Customers & 500 & 500 \\
Marketing expenditure & 300 & 600 \\
Sales & 4,000 & 4,000 \\
Operating profit & 600 & 600 \\
Acq. Cost per Cust. & 0.6 & 1.2 \\
$\begin{array}{l}\text { Revenue per } \\
\text { customer }\end{array}$ & 8.0 & 8.0 \\
$\begin{array}{l}\text { Op. profit per } \\
\text { customer }\end{array}$ & 1.2 & 1.2 \\
$\begin{array}{l}\text { Revenue per £1 } \\
\text { marketing }\end{array}$ & 13.3 & 6.7 \\
$\begin{array}{l}\text { Op. profit per } £ 1 \\
\text { marketing }\end{array}$ & 2.0 & 1.0 \\
\hline
\end{tabular}


historic costs with earnings data, however, allows the calculation of returns on marketing investment to enable valuable insights for the management and development of effective marketing strategy, particularly on a segmented basis. In the above example, Company A's marketing investment is twice as effective as Company B's.

Ascertaining the customer acquisition cost is blurred by the purpose and behaviour of the typically diverse range of marketing initiatives employed by most businesses. The cost and benefits of a direct mail campaign aimed at acquiring new customers are clear. In contrast, a highprofile campaign geared towards raising awareness should complement and facilitate future acquisition-driven marketing initiatives; however, this expenditure also has an impact on other operating aspects of the business such as supplier negotiations, recruitment, investor relations and staff satisfaction. Should some or all of this expenditure be included when valuing on a historic cost basis? It is also interesting to note that the same marketing expenses would be used to calculate brand value on a cost basis, thus highlighting further fallibility of cost-based approaches.

The strength of cost-based intangible assets valuations lies in the simplicity of application; however, for more accurate and meaningful valuation exercises, it is clear that more refined and advanced techniques are required.

\section{Market methodologies}

Given that intangible assets such as brands are unique by definition, it is slighty ironic that an approach based on market comparable transactions is recommended. In the same way as using profit and revenue multiples to value companies, recent transactions involving the sale of brands or customers can provide a useful 'rule of thumb' for valuing similar intellectual property rights.
The primary weakness of this approach is the availability of sufficiently comparable transactions. Unlike shares in listed companies, which are traded on a daily basis, intangible assets are rarely acquired individually. Furthermore, when acquired as part of a business, the individual intangible asset values may not be separately identified or key performance metrics reported.

Attempting to value the intangible assets of the Constellation Brand's acquisition of Fortune Brands' wine business demonstrates the complexity and difficulty of the market approach. Constellation paid $\$ 884.5 \mathrm{~m}$ for the Clos Du Bois, Geyser Peaks and Wild Horse brands, 2.6m cases of stock, 15,000 acres of vineyards and five wineries. Despite numerous transactions in the alcoholic beverages sector, there are few acquisitions where an acquired brand is valued separately (such as in United Breweries' acquisition of White \& MacKay, which reported the acquired brand value separately ¿180m out of a total transaction value of $£ 595 \mathrm{~m})$. Does the value of a whisky brand predominantly operating in European markets provide a reasonable benchmark to the value of wine brands predominantly sold in the US? Diageo's acquisition of Montana Wines in 2005 would be a more suitable comparison but in this instance the value of all intangibles acquired (€371m) was reported collectively and not identified. separately. Even an acquisition involving the same brands provides little insight. The wine brands sold to Constellation were originally acquired by Fortune Brands as part of a larger acquisition of a number of wine and spirit brands from Allied Domecq in 2005. Again, the values of the intangible assets acquired were reported collectively and this therefore provides little insight into the intangible value of the recent transaction.

Even where data are available for sufficiently comparable transactions, it is important to consider how this value was determined and the scope of the intangible asset in question. This essential information 
is rarely disclosed. If the value of a comparable brand as part of a recent transaction was determined using historic cost, using such a value for comparative valuation purposes compounds the weakness inherent in the cost approach and would deviate from a value determined using the brand's own acquisition costs. The value used for comparison could itself have been based on the valuation of other comparables and consequently does not inspire confidence. An income-based valuation used for comparison may include highly sensitive key assumptions that may not be applicable to the intangible asset to be valued.

\section{Income approach}

Income approaches are based around the concept that an asset's worth is equal to the present value of the future returns the asset is expected to generate. This involves forecasting the entity or asset's ability to generate cash and adjusting the future income streams to today's value by discounting for risk.

There are several income-based methods that are appropriate for intangible assets

- Royalty relief

- Intangible asset contribution

- Multiple-period excess earnings.

Royalty relief - Estimates the present value of the royalties less tax and associated costs that the business would have to pay if it did not own the asset in question. This approach is commonly used for brands and patents because there is an active licensing market that makes it relatively straightforward to find comparable licensing transactions to estimate an appropriate valuation royalty rate. This approach is not very helpful when valuing a customer relationship as it is not an asset that is typically licensed, and hence there is nouniverse of comparable transactions. Intangible Asset Contribution - Recognises the contribution of intangible assets to the business earnings. These are then discounted back to give a present value. The weakness of this approach is in determining the appropriate intangible asset contribution internal and external benchmarks are difficult to assess and obtain while econometric analysis or trade-off research needed to obtain a reasonable level of accuracy would be expensive and still not be particularly robust. Using this approach, the intangible assets of a loss-making business would be worth nothing, which, in the case of a business whose manufacturing base is expensive or inefficient, may be very far from the truth such that only the intangible assets have a disposal value should the business go bust.

Multiple-period excess earnings - The value of expected economic benefits that exceed an appropriate rate of return on the value of a selected asset base being used to generate anticipated economic benefits. Basically, subtract the present value of costbased returns for each operating function and any separately identifiable intangibles from the entity's business value. This is a commonly used approach for valuing customer-related intangibles.

Table 2 presents a simplistic example of the multiple excess earnings approach. First, the business value is calculated. Future returns on the costs of key functions are discounted to a present value; a more

Table 2: Multiple-period excess earnings example

\begin{tabular}{lllr}
\hline $\begin{array}{l}\text { Business } \\
\text { value }\end{array}$ & & & 109.0 \\
\hline & $\begin{array}{l}\text { Rate of } \\
\text { return }\end{array}$ & $\begin{array}{l}\text { Present value } \\
\text { of functional } \\
\text { returns }\end{array}$ & \\
$\begin{array}{l}\text { Manufacturing } \\
\text { Distribution }\end{array}$ & $8 \%$ & 45.6 & \\
Administration & $11 \%$ & 5.5 & 59.9 \\
& $13 \%$ & 8.7 & \\
& $\begin{array}{l}\text { Royalty } \\
\text { rate }\end{array}$ & $\begin{array}{l}\text { Present value of } \\
\text { royalty income }\end{array}$ & \\
Brand value & $5 \%$ & 41.9 & 41.9 \\
Excess returns & & & 7.2 \\
\hline
\end{tabular}


detailed analysis would include the present value of returns of a larger number of discrete functions such as IT, HR and R\&D. By calculating brand value using the royalty relief approach, there is no need to determine the present value of functional returns on marketing expenditure.

Subtracting the value of all identified intangibles and the present value of functional returns from the business value leaves a residual amount of excess returns. Assuming a value has been allocated to all operating functions and intangible assets, the value of the excess returns is equivalent to the value of the customer relationship.

This approach and rational is similar to the concept of the value chain framework where the value of the whole chain is greater than the sum of its parts. In this way, the value of the customer relationship can be considered as the additional value created from assets employed in combination over and above normal functional returns.

The principal weakness of the multiple excess earnings approach is that it is complicated to carry out. Furthermore, correctly identifying all the value drivers (operating functions and intangible assets employed) and calculating their respective functional returns and present values is open to distortion and inaccuracy due to the sensitivity of the valuation to key assumptions and source data. In the case of an acquisition, the excess returns will also include the value of any synergies resulting from the business combination.

\section{CONCLUSION}

Valuing intangible assets, in particular customer-related intangibles, is clearly not a straightforward exercise. Each valuation method prescribed by accountants has different strengths, weaknesses and complexities and yet none are able to provide an indisputably accurate and reliable value. Although these values are not as robust as we would hope, it is certainly better to attempt to attribute value to intangible assets than classifying everything as goodwill.

Many appraisers specialising in intangible assets would typically consider all three valuation approaches but in most instances rely on an income-based approach as a primary method and use market-based approaches for supporting evidence. Multiples of revenues, profits and assets, and other such rules of thumb are sufficient for benchmarking and as a sense check but are by no means robust enough to be relied upon in their own right. During the dot. com madness, many of the inflated valuations were due to lazy investment appraisals based on spurious rules of thumb such as customer lifetime value. In this way, valuing intangible assets is more of an art than a science; applying several supporting methodologies and a modicum of common sense provides sufficient confidence in a valuation result.

In any case, regardless of whether you call the asset brand, customer relationship or whatever, fundamentally what we are attempting to evaluate is management's ability to manage customer relationships while profitably exploiting the assets employed.

For strategic purposes, the value of an intangible asset in its own right is not particularly relevant; however, an understanding of how this value is comprised and the key metrics that impact on the assets' contribution to business performance can be extremely beneficial for management decision making. Common business performance metrics such as profit or revenue per customer, returns on investment, capital employed or assets, brand awareness, preference, response rates, retention and lapse rates are ultimately far more pertinent to day-to-day business management and longer-term planning than any spurious intangible asset value.

Successful businesses are skilled at managing their customers profitably. After all, customers are the reason for the businesses' existence. 